\title{
Fatal Nemaline Myopathy in Infancy
}

\author{
Joseph B. McMenamin, Bernadette Curry, Glen P. Taylor, Laurence E. Becker, and \\ E. Gordon Murphy
}

\begin{abstract}
The clinical and neuropathological findings in two infants with congenital nemaline myopathy are described. One patient presented at birth with severe hypotonia, respiratory failure and contractures and died shortly after the neonatal period. The other presented at age two months with hypotonia and, following a period of clinical stability, died at age seven months from respiratory failure. Pathological findings in the fatal neonatal case revealed numerous rod bodies in lingual, pharyngeal, diaphragm and limb muscles, correlating with clinical findings. Significant, but less rod body involvement was found in the diaphragm and limb muscles of the second patient. Although a neural basis has been suggested for this disorder, no abnormalities were found in the central nervous system or in the peripheral nerves of these two severely affected patients.
\end{abstract}

RÉSUMÉ: Nous décrivons les caractéristiques cliniques et neuropathologiques de deux nourissons avec une myopathie némaline congénitale. Un patient est né avec une hypotonie sévère, une insuffisance respiratoire et des contractures, et il est mort peu après la période néonatale. Le deuxième patient montra à deux mois une hypotonie et devait mourir d'insuffisance respiratoire à 7 mois après une période de stabilité. Chez le premier enfant la neuropathologie a montré de nombreux corps en bâtonnet dans les muscles de la langue, du pharynx, du diaphragme et des membres. Chez le second patient les mêmes bâtonnets, mais en nombre inférieur, furent trouvés dans les muscles du diaphragme et des membres. Malgré l'hypothèse d'une base neurale pour cette maladie, il fut impossible de trouver des anomalies du CNS ou des nerfs périphériques chez ces deux patients.

Can. J. Neurol. Sci. 1984; II:305-309

Congenital nemaline myopathy (CNM) is a rare muscle disorder characterized by the presence of nemaline rods in skeletal muscle fibers (Bender, 1980; Brooke, 1977; Dubowitz, 1978). Over 50 cases of CNM have been reported in the literature (Kondo and Yuasa, 1980) since the first description of the disease in 1963 (Conen, Murphy, Donohue and Shy, Engel, Sommers, Wanko). However, clinical and pathological details of cases presenting in infancy, and particularly in the newborn period, are few and incomplete. Since our first case report of CNM (Conen, Murphy, Donohue, 1963) we have diagnosed eight children with this myopathy and two have succumbed in infancy. The purpose of this paper is to describe the contrasting clinical and pathological features of these two fatal cases.

\section{CASE REPORTS}

Case 1: This male infant was born to a 22 year old healthy primagravida following a normal pregnancy. There was no family history of neuromuscular disease. Labor was spontaneous at term, and because of failure to progress, the infant was delivered by cesarean section. At birth oligohydramnios was noted and the amniotic fluid was darkly stained with meconium. The infant was hypotonic and failed to initiate spontaneous respirations. The apgar scores were 2 and 7 at one and five minutes respectively, the infant was intubated and given intermittent positive pressure ventilation. Once stabilized, he was transferred to the neonatal intensive care unit. On examination he had no movements with doll's head maneuver, facial diplegia, and poor sucking and swallowing reflexes. Deep tendon reflexes could not be elicited. There was no muscle fasciculation. He had bilateral talipes equinovarus deformities of the feet with flexor contractures of both knees and hips. There were no dysmorphic features. He remained hypotonic, continued to have progressive respiratory difficulties, and could not be weaned off the ventilator. Chest radiograph was normal. Routine cultures and biochemistry, including metabolic screening, were normal. Chromosome analysis showed a normal male karyotype. Electroencephalogram on the fourth day of life revealed poorly organized background rhythms with sharp transients from the right hemisphere. Computed tomography of the brain was normal. Because of the persistent hypotonia and failure to initiate spontaneous respirations, a neuromuscular disorder was suspected. Serum CK was 91 IU/Litre $(\mathrm{N}<100)$ and EMG was normal. A muscle biopsy was taken from the right quadriceps muscle on the thirteenth day of life. The specimen was processed and stained as previously described (McMenamin. Becker and Murphy, 1982). With the modified Gomori trichrome method, masses of red rod deposits were identified in the smaller fibers which on myosine ATPase staining were type I fibers (Fig. 1). The type I fibers were small with a sharp. single peak at 10 microns. Electronmicroscopic studies showed numerous electron dense rods measuring up to $5 \mu \mathrm{m}$ in length and $1.5 \mu \mathrm{m}$ in diameter (Fig. 2). At the border of the rods, continuity with thin filaments was evident (Fig. 3). Despite continued supportive ventilation. the patient expired at six weeks of age.

From the Departments of Paediatrics and Pathology (Neuropathology), University of Toronto and the Division of Neurology, The Hospital for Sick Children, Toronto Received August 30, 1983. Accepted in revised form January 8, 1984

Reprint requests to: Dr. E. G. Murphy, Division of Neurology, The Hospital for Sick Children, 555 University Avenue, Toronto, Ontario, Canada M5G IX8 
Autopsy examination revealed an abundance of nemaline rods in many skeletal muscles with marked involvement of the diaphragm and intercostal groups. Numerous rods were also present in the pharyngeal muscles and in the tongue. No rods were found in the myocardium or smooth muscles of the gastrointestinal tract on light microscopy or electronmicroscopy. The brain was grossly and microscopically normal. The spinal cord was sectioned horizontally and ten representative levels taken for histological examination. No anterior horn cell loss or astrogliosis was present. The peripheral nervous system was widely sampled: a left vagus nerve, left intercostal nerve, right median nerve, right musculocutaneous nerve, left femoral nerve, right peroneal nerve, and right sural nerve. Conventional histology using myelin (luxol fast blue) and axon (Bielschowsky) stains showed no abnormality. A portion of the sural nerve was also placed in Universal fixative and processed, as previously described (Sachas, Armstrong, Becker and Byran, 1982). The number and size distribution of myelinated fibers was determined (Fig. 4a) using thin plastic sections stained with toluidine blue. The histogram was comparable to a normal age-matched control case (Fig. $4 \mathrm{c}$ ), and showed a normal maturational fiber distribution (Gutrecht and Dyck, 1970 and Origuchi, 1981). Other autopsy findings were severe atelectasis of the left lung with focal bronchopneumonia. Death was attributed to respiratory failure from atelectasis, consolidation and respiratory muscle failure.

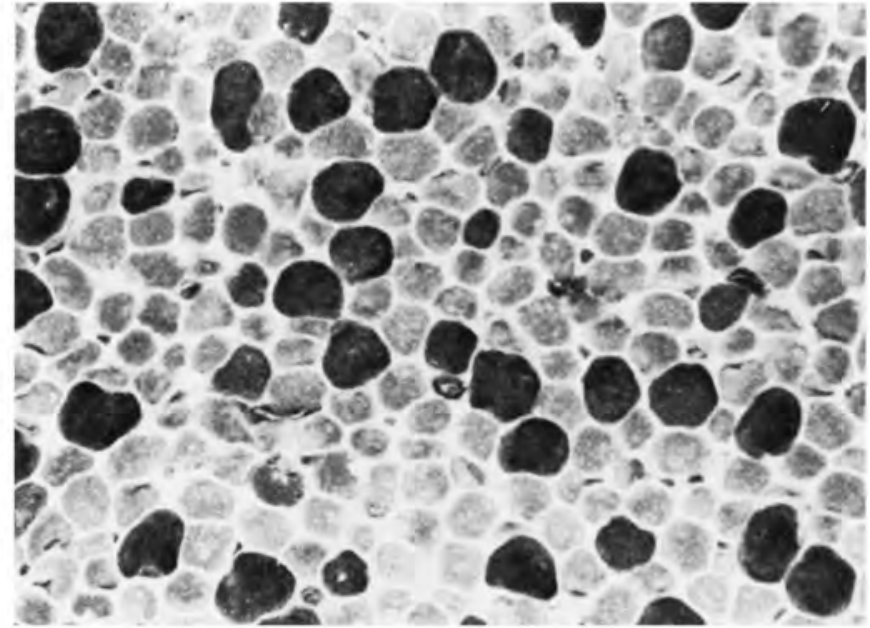

Figure 1 - Biopsy of right quadriceps muscle from Case I illustrating mainly small Type I fibers. ATPase ( $p H$ 9.4) X 640 .

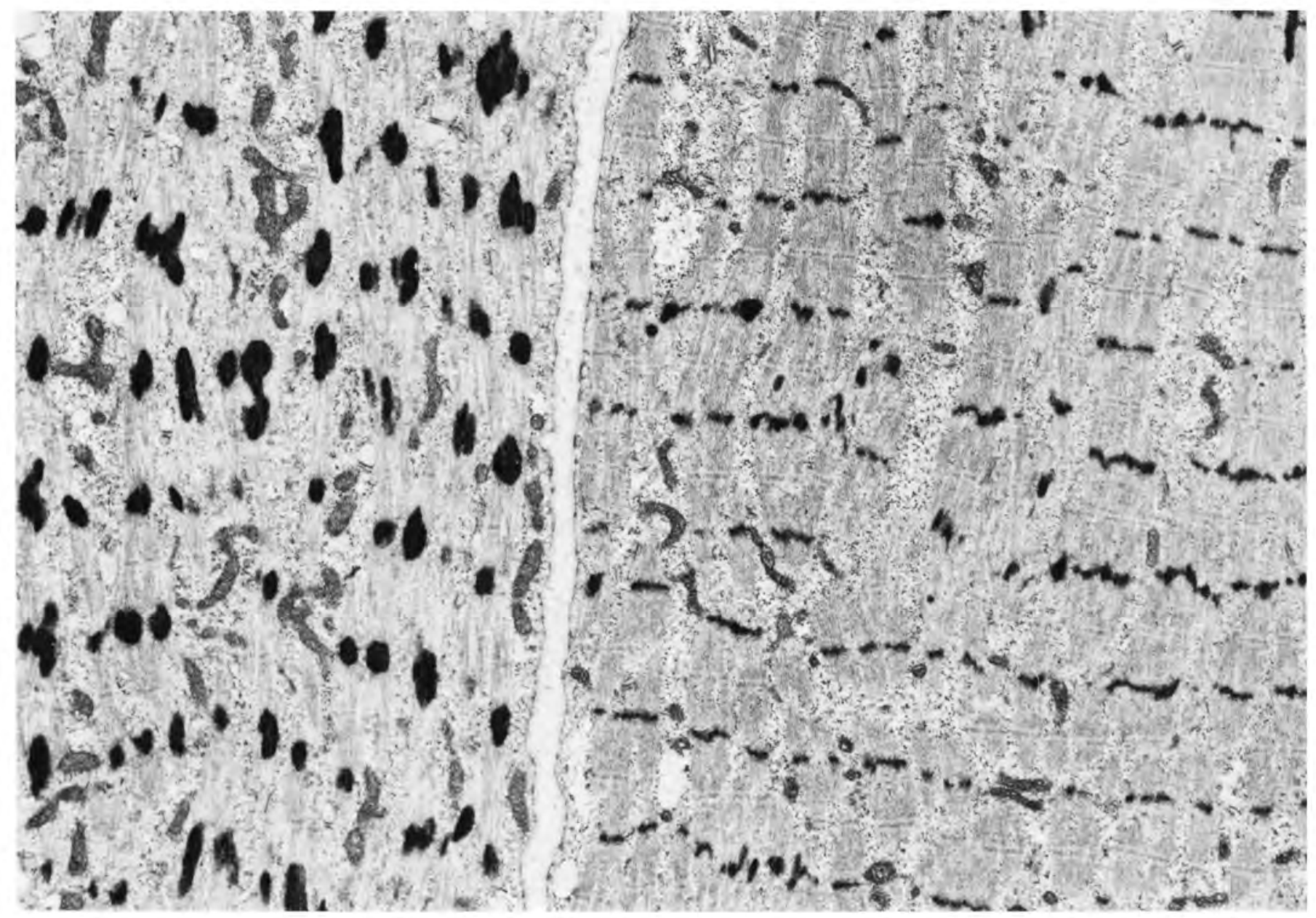

Figure $2-$ In the myofibril on the left there is mild thickening and irregularity of $Z$ lines and on the right in the position of the $Z$ lines, there are irregular, large osmiophilic, dense "rods". Case 1. Electron micrograph X 6,667. 


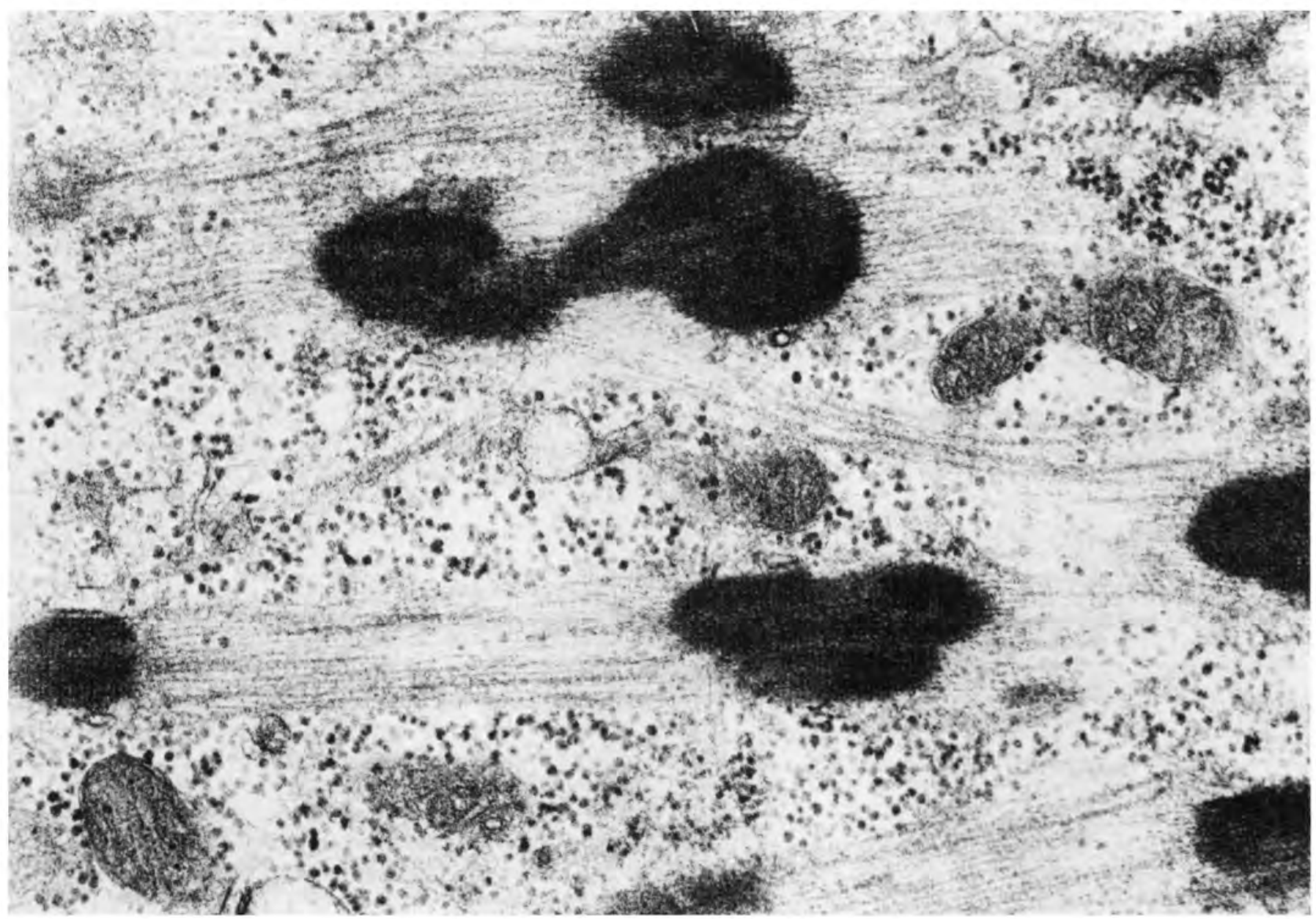

Figure 3 - Characteristic lattice structure of rod bodies with suggestive continuity with myofilaments is illustrated. Case I. Electron micrograph X $28,770$.

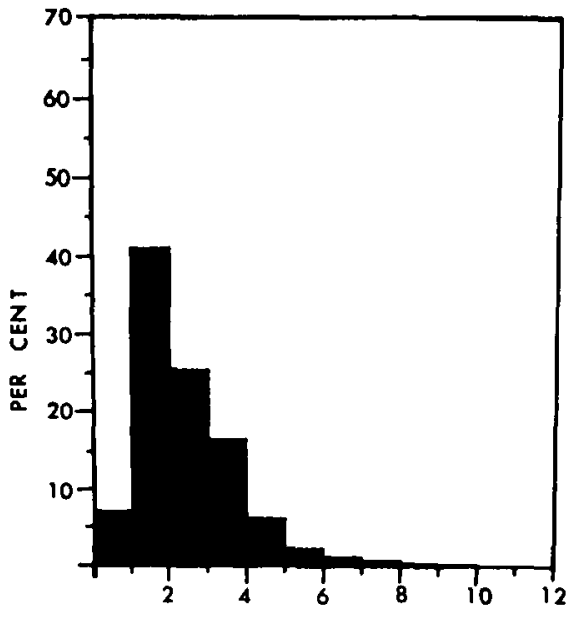

MYELINATED FIBER DIAMETERS IN MICRONS

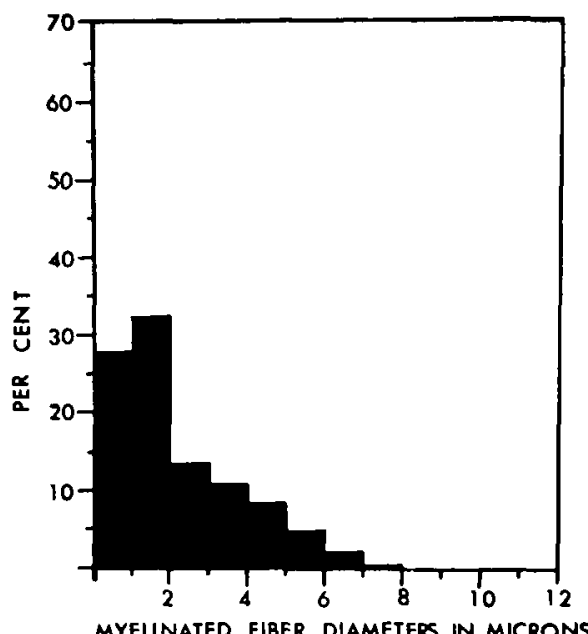

MYELINATED FIBER DIAMETERS IN MICRONS

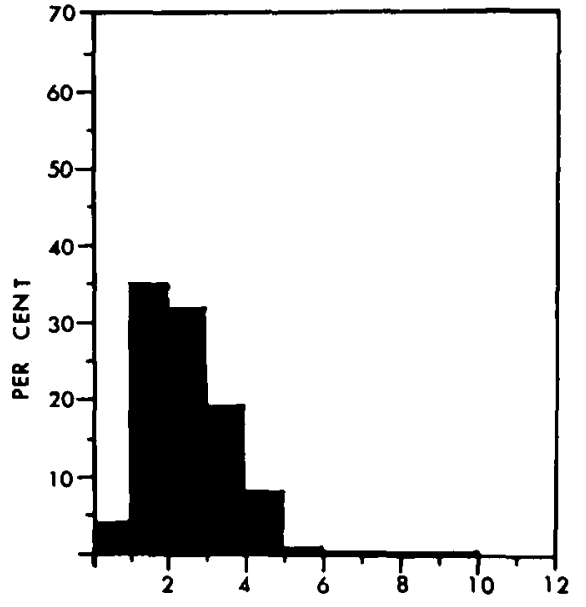

MYELINATED FIBER DIAMETERS IN MICRONS

Figure 4-Distribution of diameters of the myelinated nerve fibers in the sural nerves in a) Case $1, b$ ) Case 2 and c) normal control infant. 
Case 2: A two month old female infant presented with hypotonia from birth. She had a female sibling who died at six months of age who was also hypotonic from birth. A neuromuscular disorder was clinically suspected in this patient but unfortunately no investigative or pathological studies were performed. The patient had one healthy male sibling, both of her parents were clinically normal, and there was no other history suggestive of neuromuscular disease in the family. She was born at term without complication and her birthweight was $3.9 \mathrm{~kg}$. Although hypotonic, her neonatal course was otherwise normal. Examination at age two months revealed a well nourished child without dysmorphic features. Her cranial nerves were normal. She had moderate generalized hypotonia and depressed deep tendon reflexes. Serum CK, EMG, and motor nerve conduction velocities were normal. Computed tomography of the brain was normal. On follow-up evaluation at age five months the infant appeared to be clinically stable. Although she remained hypotonic she was making progress in her motor development. She had no muscle wasting, hypertrophy, or fasciculations and her deep tendon reflexes remained depressed. At age seven months she developed progressive respiratory difficulties over a two week period. Examination revealed moderate to severe muscle weakness with hypotonia and areflexia. Her respirations were rapid and shallow. The patient developed progressive respiratory distress. She subsequently required ventilatory support, but died on the second hospital day of respiratory failure.

Autopsy examination revealed the presence of nemaline rods involving all skeletal muscles examined. The rods were histochemically and ultrastructurally similar to Case 1. On myosin ATPase staining, the type I fibers were predominant and small. The peak fiber diameter was 10 microns. Type 11 fibers were larger and had peak diameters ranging from 20-40 microns. The number of rods was greatest in the quadriceps and anterior tibialis muscles and least in the diaphragm and intercostal groups. The biceps and brachioradialis muscles showed an intermediate degree of involvement. Nemaline rods were found in all samples of skeletal muscle that were examined. No nemaline rods were seen either by light microscopy or electron microscopy of the heart. Nemaline rods were absent in the smooth muscle of the gastrointestinal tract. Gross and microscopic examination of the brain revealed no abnormalities. Sectioning the spinal cord at $0.5 \mathrm{~cm}$. intervals and examining representative levels revealed no anterior horn cell loss or astrogliosis. The right femoral nerve, right phrenic nerve and right sural nerve showed no abnormalities of axons or myelin. The myelinated fibers of the sural nerve were quantitated and the histogram (Fig. 4B) showed no significant alteration from an age-matched control case. Other autopsy findings included focal bronchopneumonia, mucous plugging of the left main stem bronchus and total atelectasis of the left lung. Death was attributed to respiratory failure from atelectasis and respiratory muscle failure.

\section{Discussion}

Congenital Nemaline Myopathy, first described by Shy et al. (1963) and Conen et al. (1963), is a congenital myopathy with a very distinctive histological appearance. The clinical features include congenital hypotonia of variable degree, generalized weakness, facial weakness, high arched palate, frequent skeletal deformities, contractures, reduced or absent tendon reflexes and myopathic EMG changes (Bender, 1980 and Dubowitz, 1978). The mode of inheritance of CNM is variable but considered to be autosomal dominant with reduced penetrance in most cases (Kondo and Yuasa, 1980). As in central core myopathy, a disorder with an equally distinctive histological pattern, the clinical course has been described as either non-progressive or slowly progressive (Bender, 1980; Brooke, 1977 and Dubowitz, 1978). However, two syndromes presenting in infancy are now recognized (Volpe, 1981). A non-progressive or slowly progressive form presenting with mild hypotonia at birth, conforming to the more common variety, and a more severe, less common form with marked hypotonia, muscle weakness and pulmonary failure from respiratory muscle weakness.

The clinical presentation of our two patients sharply contrasted with each other. Case I presented with the severe, less common form of the disease. He was initially managed as an infant with hypoxic-ischemic encephalopathy. Intrauterine hypotonia may predispose the infant with a congenital neuromuscular disorder to hypoxic-ischemic injury at birth, and this may mask the primary underlying disease. This patient was similar to the cases reported by Gillies et al. and McComb et al. (1979). In addition to other congenital abnormalities, the case of McComb et al. had bilateral talipes equinovarus. This abnormality which is likely due to muscle contracture resulting from decreased intrauterine motor activity, is found in other neuromuscular disorders presenting at birth including congenital myotonic dystrophy (Harper, 1975) and congenital muscular dystrophy (McMenamin, Becker and Murphy, 1982). The presence of this finding in the newborn infant, particularly when associated with persistent feeding difficulties, failure to initiate spontaneous respirations, muscle weakness and absent or depressed deep tendon reflexes should alert the physician to the possibility of an underlying congenital neuromuscular disorder.

The autopsy findings in infants with CNM have been reported (Eeg-Olofsson et al., 1983; Gillies et al., 1979; Kolin, 1967; Matsuo et al., 1982; Neustein, 1973; Norton et al., 1983 and Shafiq et al., 1967). Pertinent information on findings in the nervous system has been lacking, and no studies of peripheral nerves have been described. Nemaline rods have been found in variable amounts in most skeletal muscles including the tongue, pharynx, diaphragm and intercostal groups. It has been stated that the number of rods does not always correlate with the degree of weakness in a given muscle (Bender, 1980). However, the early severe diaphragmatic involvement with rod bodies in Case 1 was associated with profound respiratory failure, and this has been noted in at least one other fatal neonatal case (McComb et al., 1979). The equally striking tongue and pharyngeal involvement correlated with the feeding difficulties in this patient. This clinicopathological correlation may be more prominent in the severe neonatal form of the disease. The absence of smooth muscle and cardiac involvement has been noted in some of the other autopsied cases (McComb et al., 1979 and Shafiq et al., 1967).

Case 2 presented with the less severe form of the disease. This variety is not typically associated with a rapidly progressive clinical course (Bender, 1980 and Volpe, 1981). Despite a period of clinical stability, she deteriorated dramatically and subsequently died from her primary disease. This type of clinical course has been described in one other fatal case in infancy (Shafiq, Dubowitz, Peterson and Milhorat, 1967). Thus, a favorable prognosis cannot reliably be given if the patient presents in a relatively asymptomatic manner in early infancy having survived the neonatal period. Neustein (1973) stated that the disease was fatal in approximately one out of five reported cases in infancy and this is consistent with our experience.

Although the inheritance of CNM in most cases is considered to be autosomal dominant with reduced penetrance (Kondo and Yuasa, 1980), an autosomal recessive mode of inheritance could also be implicated in our second case. Muscle biopsies were not obtained from the parents who were both clinically asymptomatic.

The rod body is thought to be a lateral expansion of the $\mathrm{Z}$ band which is normally found at either end of the sarcomere in which the thin contractile filaments are embedded (Price et al., 1965). Recent evidence suggests that the rod body may in fact represent actin (Jennekens et al., 1983 and Yamaguch et al., 
1978). Another histological feature of CNM, also clearly evident in our patients, was the predominance of small type-I fibers. This finding is considered by some to represent a paucity of type II fibers and, therefore, a selective loss of type II motor neurons (Engel, 1970 and Karpati et al., 1971). Neurogenic findings at EMG have been described in infants with CNM (McComb et al., 1979, Neustein, 1973 and Norton et al., 1983) and a reduced number of anterior horn cells in the spinal cord has been described in an older patient (Dahl and Klatzow, 1974), thus suggesting a neural basis for this disorder. However, no neurogenic findings were evident at EMG in our patients. Although a functional defect cannot be excluded, we found no abnormality in the central nervous system or of peripheral nerves in these two severely affected infants.

\section{ACKNOWLEDGEMENTS}

We would like to thank Mrs. Virginnia Adamson for typing the manuscript.

\section{REFERENCES}

Bender AN (1980) In: Vinken PJ, Bruyn GW (eds) Handbook of Clinical Neurology Vol. 41, Part 2. Diseases of Muscle, New York, Elsevier, pp. 1-26.

Brooke MH (1977) A clinicians view of neuromuscular diseases. Williams and Wilkins, p. 209.

Conen PE, Murphy EG, Donohue WL (1963) Light and electron microscopic studies of "myogranules" in a child with hypotonia and muscle weakness. Can. Med. Assoc. J. 9: 983.

Dahl DS, Klatzow FW (1974) Congenital rod disease. Further evidence of innervation abnormalities as the basis for the clinicopathological features. J. Neurol. Sci. 23: 371.

Dubowitz V (1978) Muscle disorders in childhood. London, W.B. Saunders.

Eeg-Olofsson O, Henriksson KG, Thornell LE, Wesstrom G (1983) Early infant death in nemaline (rod) myopathy. Brain Dev. 5: 53.

Engel WK (1970) Selective and non-selective susceptibility of muscle fiber types. Arch. Neurol. 22: 97.

Gillies C, Raye J, Vasan R, Hart WE, Goldblatt PJ (1979) Nemaline (rod) myopathy. Arch. Pathol. Lab. Med. 103: 1.
Gutrecht JA, Dyck PJ (1970) Quantitative teased-fibre and histological studies of human sural nerve during postnatal development. J. Comp. Neurol. 138: 117.

Harper PS (1975) Congenital myotonic dystrophy in Britain 1. clinical aspects. Arch. Dis. Child 50: 505.

Jennekens FGI, Roord JJ, Veldman H, Willemse J, Joskusch BM (1983) Congenital nemaline myopathy. I. Defective organization of alpha-actinin is restricted to muscle. Muscle \& Nerve 6: 61 .

Karpati LG, Carpenter S, Andermann F (1971) A new concept of childhood nemaline myopathy. Arch. Neurol. 24: 291.

Kolin IS (1967) Nemaline myopathy: A fatal case. Amer. J. Dis. Child 114: 95 .

Kondo K, Yuasa $T$ (1980) Genetics of congenital nemaline myopathy. Muscle \& Nerve 3: 308.

Matsuo T, Tashiro T, Ikeda T, Tsujihata M, Shimomura C (1982) Fatal neonatal nemaline myopathy. Acta Pathol. Jpn. 32: 907.

McComb RD, Markesbery WR, O'Connor WN (1979) Fatal neonatal nemaline myopathy with multiple congenital anomalies. J. Petiatr. 94: 47.

McMenamin JB, Becker LE, Murphy EG (1982) Congenital muscular dystrophy, a clinicopathological report of 24 cases. J. Pediatr. 5: 692.

Neustein HB (1973) Nemaline myopathy: A family study with three autopsied cases. Arch. Pathol. 96: 192.

Norton P, Ellison P, Suliaman AR, Harb J (1983) Nemaline myopathy in the neonate. Neurology 33: 351.

Origuchi $Y(1981)$ Quantitative histological study in the sural nerves of children. Brain Dev. 3: 395.

Price HM, Gordon GB, Pearson CM, Munsat TL, Blumberg TM (1965) New evidence for excessive accumulation of Z-band material in nemaline myopathy. Proc. Natl. Acad. Sci. (USA) 54: 1398.

Sachis PN, Armstrong DL, Becker LE, Byran AC (1982) Myelination of the human vagus nerve from 24 weeks post-conceptional age to adolescence. J. Neuropath. Exp. Neurol. 41: 466.

Shafiq SA, Dubowitz V, Peterson H de C, Milhorat AT (1967) Nemaline myopathy: Report of a fatal case, with histochemical and electron microscopic studies. Brain 90: 817.

Shy GM, Engel WK, Sommers JE, Wanko T (1963) Nemaline myopathy, a new congenital myopathy. Brain 86: 793.

Volpe JJ (1981) Neurology of the Newborn. Philadelpíia, W.B. Saunders, p. 468.

Yamaguchi M, Robson RM, Stromer MH, Dahl DS, Uda T (1978) Actin filaments form the backbone of nemaline myopathy rods. Nature 271: 265. 